\title{
The Rise of Reptiles: 320 Million Years of Evolution
}

\author{
Hans-Dieter Sues \\ Johns Hopkins University Press, ISBN 9781421428673, pp. 385, hardback
}

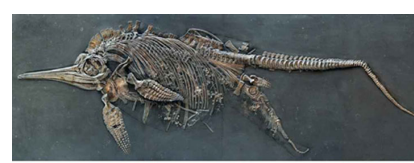

Come would say that the Sreptiles don't exist, so why, one might ask, is there a book about their evolution? THE RISE OF REPTILES

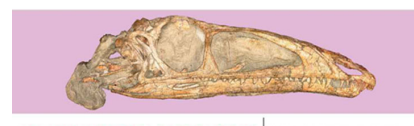
This denial of existence is a bit of word-play though. The critics mean that there is no formal clade Reptilia, because 320 MILLION YEARS OF EVOLUTION $\mid$ HANS-DiETER SUES $\frac{(x+2)}{2+292}$ birds and mammals evolved from reptilian ancestors, and so the group is paraphyletic because they are excluded from its definition. But we all know what reptiles are today, and their past has been much richer and significant than the current crop of lizards, snakes, crocodiles and turtles might suggest.

Hans-Dieter Sues has produced a book in the style of his mentor, the great Bob Carroll, whose 1988 vertebrate paleontology textbook was a substantial update of the 1966 text by Al Romer (1894-1973), so the present book has a long and distinguished pedigree. Characteristic of these works is a focus on diversity and anatomy, with crisp text matched by excellent illustrations, often carefully crafted drawings, of the fossils and reconstructions of skulls and skeletons. Here we have all of that, but with the addition of colour photographs of fossils and living animals, as well as a modern phylogenetic setting throughout.

Introductory chapters explain the basics of fossils, geological time, anatomical terminology, and the importance of amniotes and reptiles. As in the precursor Romer and Carroll volumes, the remainder is a thorough coverage, group by group, from parareptiles to dinosaurs, with turtles, marine reptiles, lepidosauromorphs, and archosauromorphs in between. For each group, there is a brief history and then a review of key diagnostic characters, taxa, adaptations, and functions. The illustrations include the best available specimen drawings and colour photographs, obtained from dozens of researchers, so many have never featured in a book before, and they are very well reproduced. Sues has redrafted some older figures to add colour and explanation. A further good feature is that each clade is introduced with a standardized cladogram of major taxa, showing the current best estimate of relationships.

There are different ways to write such a book, and the chapter on Avemetatarsalia (bird-line archosaurs) can illustrate this. Here, we are introduced to the various close relatives of dinosaurs, including pterosaurs, and much of the work is recent, with papers from 2017 and 2018 cited for the Aphanosauria, Silesauridae, and some new pterosaurs. The text is clear in defining the various clades, and providing a rational sequence of taxa, and highlighting key characteristics of each. The figures are a mix of colour photographs of specimens, drawings and some sharp whole-body images of these slick little pre-dinosaurs by Scott Hartman, Carol Abraczinkas and others. This gives an excellent and up-todate overview of who was who and why, when they lived, and where they sit in the evolutionary tree.

There are some hints at paleobiology ("features suggest omnivorous or herbivorous habits"), but not much, and there are no life restorations such as colour paintings of animals in their habitats. Nor is there anything about macroevolution or macroecology. For example, why were these avemetatarsalian groups diversifying in the Triassic (perhaps part of the recovery fauna from the devastating end-Permian mass extinction; perhaps part of an arms race between synapsids and archosauromorphs as they adopted erect posture and some form of warm-bloodedness)? Debates, discussions and data about triggers for the origin and diversification of the dinosaurs are not included. Computational modelling of jaw and limb mechanics are excluded. However, this sits perfectly in the long tradition of the fundamentals of vertebrate paleontology with the focus on getting the framework right, based on careful exploration of anatomy, and the search for phylogenetically informative characters. Clarity about anatomy and phylogeny are essential before exploring broader themes in function and macroevolution, and such topics are well covered elsewhere.

The writing style is clear and easy, the illustrations are excellent, and the whole design and print quality highly attractive. There is no other book like it, and this will stand as a useful reference for many years. It is also the same size and shape as Romer's and Carroll's books, so I will squeeze them up side-by-side on my book shelf. The hardback volume retails for around $£ 57$, Kindle edition slightly less.

\section{MICHAEL J. BENTON}

School of Earth Sciences, University of Bristol, Life Sciences Building, Tyndall Avenue, Bristol, BS8 1TQ, UK

Email: mike.benton@bristol.ac.uk

Received: 3 November 2019 